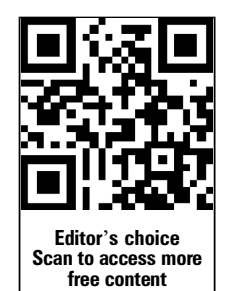

free content
- Additional material is published online only. To view please visit the journal online (http://dx.doi.org/10.1136/ bjsports-2014-093543).

${ }^{1}$ Faculty of Kinesiology, Sport Injury Prevention Research Centre (SIPRC), University of Calgary, Calgary, Alberta,

Canada

${ }^{2}$ Department of Sports Medicine, Oslo Sports Trauma Research Centre, Norwegian School of Sport Sciences, Oslo, Norway

${ }^{3}$ Australian Centre for Research into Injury in Sport and its Prevention (ACRISP), Federation University Australia, Ballarat, Australia

${ }^{4}$ Faculty of Medicine, Department of Pediatrics, Alberta Children's Hospital Research Institute for Child and Maternal Health, University of Calgary, Calgary, Alberta, Canada

${ }^{5}$ Faculty of Medicine, Department of Community Health Sciences, University of Calgary, Calgary, Alberta,

Canada

${ }^{6}$ Faculty of Medicine, Hotchkiss Brain Institute, University of Calgary, Calgary, Alberta, Canada

\section{Correspondence to} Carly D McKay, Faculty of Kinesiology, Sport Injury Prevention Research Centre (SIPRC), University of Calgary,

Calgary, Alberta,

Canada T2N 1N4;

cdmckay@ucalgary.ca

Received 6 February 2014 Revised 14 May 2014 Accepted 28 May 2014 Published Online First 13 June 2014

\title{
The effect of coach and player injury knowledge, attitudes and beliefs on adherence to the FIFA 11+ programme in female youth soccer
}

\author{
Carly D McKay, ${ }^{1}$ Kathrin Steffen, ${ }^{2}$ Maria Romiti, ${ }^{1}$ Caroline F Finch, ${ }^{3}$ \\ Carolyn A Emery ${ }^{1,4,5,6}$
}

\begin{abstract}
Background Injury knowledge and beliefs influence uptake of prevention programmes, but the relationship between knowledge, beliefs and adherence remains unclear.
\end{abstract}

Aim To describe injury knowledge and beliefs among youth female soccer coaches and players, and to identify the relationship between these factors, different delivery strategies of the FIFA 11+ programme and adherence.

Methods A subcohort analysis from a clusterrandomised controlled trial of 31 female soccer teams (coaches $n=29$, players (ages 13-18) $n=258$ ). Preseason and postseason questionnaires were used to assess knowledge and beliefs. Teams recorded FIFA 11+ adherence during the season.

Results At baseline, $62.8 \%$ (95\% Cl 48.4\% to $77.3 \%$ ) of coaches and $75.8 \%(95 \% \mathrm{Cl} 71.5 \%$ to $80.1 \%)$ of players considered 'inadequate warm-up' a risk factor for injury. There was no effect of delivery method $(\mathrm{OR}=1.1$; $95 \% \mathrm{Cl} 0.8$ to 1.5$)$ or adherence $(\mathrm{OR}=1.0 ; 95 \% \mathrm{Cl} 0.9$ to 1.1$)$ on this belief. At baseline, $13.8 \%(95 \% \mathrm{Cl} 1.3 \%$ to $26.4 \%$ ) of coaches believed a warm-up could prevent muscle injuries, but none believed it could prevent knee and ankle injuries. For players, 9.7\% (95\% Cl 6.1\% to $13.3 \%), 4.7 \%(95 \% \mathrm{Cl} 2.1 \%$ to $7.3 \%$ ) and $4.7 \%(95 \%$ $\mathrm{Cl} 2.1 \%$ to $7.3 \%$ ) believed a warm-up would prevent muscle, knee and ankle injuries, respectively. Years of playing experience were negatively associated with high adherence for coaches ( $O R=0.93 ; 0.88$ to 0.99$)$ and players (OR=0.92; 0.85 to 0.98$)$.

Conclusions There were gaps in injury knowledge and beliefs, which differed for coaches and players. Beliefs did not significantly affect adherence to the FIFA 11+, suggesting additional motivational factors should be considered.

\section{BACKGROUND}

In Canada, soccer injuries account for over $10 \%$ of all sport injuries in youth aged 11-18 years. ${ }^{1}$ Several studies have demonstrated the injury protective effect of a neuromuscular training warm-up programme in youth soccer ${ }^{2-8}$; however, the success of these programmes when implemented in the context of real-world sports is dependent on coach and player adherence. Higher adherence has been shown to positively correspond to greater injury protective effects. ${ }^{9-11}$ Despite this, adherence to effective injury prevention measures is an ongoing challenge in community sport settings.

There is an established need for more implementation research on sport injury prevention programmes to maximise adherence and uptake of these strategies. $^{12-15}$ Yet, there has been limited attention given to factors that could promote programme adherence. ${ }^{16}$ One potential factor is knowledge regarding injury risk and prevention. Orr et $a l^{17}$ examined youth soccer coach and player knowledge of knee injury and safety practices, and found significant gaps in understanding of knee injury prevention in coaches and players. This observation is consistent with previous studies that have found limited injury awareness among coaches $^{18-21}$ and athletes ${ }^{22-24}$ in a variety of sports.

There is a paucity of research examining how coach and player knowledge directly influences injury prevention behaviour. ${ }^{25}$ Arnason et $a l^{26}$ demonstrated that increasing injury awareness did not reduce injury rates in a sample of elite male soccer players, but did not measure the effect of awareness on players' prevention behaviour. In a study of Premier Division Australian football, coaches had poor knowledge of lower limb injury prevention strategies and did not routinely incorporate prevention strategies into their training sessions. ${ }^{19}$ Fewer than $75 \%$ of players training with these coaches believed that balance, landing or cutting exercises had injury prevention benefit, and only $74 \%$ would be willing to perform injury prevention exercises during training. ${ }^{27}$ However, with such limited evidence, the extent to which coach knowledge influences prevention behaviour among their players is not yet clear.

Attitudes towards injury risk and prevention are also associated with the uptake of preventive measures among coaches ${ }^{28} 29$ and youth sport participants. $^{22} 30-36$ Perceived susceptibility to injury, ${ }^{30} 36$ social influences ${ }^{30} 3235$ and dislike of prevention strategies $^{30} 3136$ have all been shown to influence prevention behaviours in a variety of competitive and recreational sports. Specifically, lack of perceived need, ${ }^{30}$ social pressure ${ }^{32}$ and protective equipment discomfort ${ }^{36}$ have been associated with poor adherence to preventive interventions. Additional factors, such as age, may influence these attitudes. ${ }^{30}$ In youth soccer specifically, there is also some evidence that female players report higher levels of perceived injury risk than male players. ${ }^{37}$ Interestingly, direct exposure to injury prevention programmes may not be sufficient to change injury prevention attitudes. Gilchrist et $a l^{38}$ found that participating in injury prevention did not influence soccer coaches' knowledge, attitudes, beliefs or prevention behaviours across a season.

The effect of a preventive intervention on coach and player attitudes and beliefs has not yet been 
examined in youth soccer, and the relationship between knowledge, attitudes and adherence to injury prevention programmes remains unclear. The purpose of this investigation was therefore twofold. First, the study aimed to describe the baseline levels of injury knowledge, attitudes and beliefs among coaches and players. The second objective was to determine the relationship between intrinsic coach and player factors (ie, personal characteristics and beliefs), different delivery strategies of an injury prevention warm-up programme and adherence to the intervention over the course of one competitive season.

\section{METHODS}

This study is a secondary analysis of data from a clusterrandomised controlled trial (cRCT) ${ }^{39}$ investigating the effect of different delivery methods of the FIFA $11+$ injury prevention warm-up programme $\mathrm{e}^{3}$ on adherence, player injury risk and player performance. The overall design and methods of the cRCT are reported elsewhere. ${ }^{39}$

\section{Participants}

The sample was recruited from a target population of 31 female soccer teams (players aged 13-18 years) competing in the 2011 outdoor season. These teams represented 18 clubs from the top three competitive levels (tiers 1-3) of the Calgary and Edmonton Minor Soccer Associations and the Edmonton Interdistrict Youth Soccer Association in Alberta, Canada.

All participants provided informed consent prior to the start of study as per the Office of Medical Bioethics, University of Calgary.

\section{Attitudes and beliefs questionnaire}

Coaches and players completed a paper-based questionnaire assessing their coaching/playing experience, injury history, and attitudes, beliefs and knowledge about injury risk and injury prevention in youth soccer. This was administered during baseline performance testing sessions early in the soccer season and again at the conclusion of the 4-month season, allowing an assessment of changes in attitudes and beliefs resulting from exposure to the FIFA $11+$ during the season.

The questionnaire was based on a previously developed survey of junior netball coaches in Australia. ${ }^{28} 40$ There were separate coach and player versions of the questionnaire, and both underwent face validation. The player questionnaire was also pilot tested among a team of youth soccer players involved in an independent youth soccer study in a neighbouring province. Based on this pilot test, some items were rephrased as required. The study questionnaire is available as online supplementary content.

\section{Different delivery methods of the FIFA 11+}

The FIFA $11+$ is a 20 -min warm-up programme developed by FIFA Medical Assessment and Research Centre (F-MARC) to prevent lower extremity injuries among soccer players, consisting of 15 single exercises with a focus on cutting, jumping and landing technique, and on strength, plyometrics, agility and field balance components. ${ }^{3}$ Following baseline questionnaire completion, teams were cluster randomised to one of three intervention groups to evaluate the effect of different delivery methods of the FIFA $11+$ on adherence. ${ }^{39}$

Coaches from teams randomised to the 'control' group were provided with details for online access to the FIFA $11+$ programme website (http://f-marc.com/11plus/). Coaches randomised to the 'regular, coach-focused intervention group' were provided with one preseason $11+$ coach workshop (including programme instruction information about the programme's development and purpose) and copies of FIFA 11+ material (DVD, poster detailing the exercises, website information). In addition to a preseason FIFA 11+ workshop for coaches and receiving copies of the FIFA $11+$ material, teams in the 'comprehensive, player-focused intervention group' were also assigned a study physiotherapist who taught the $11+$ programme to the players and participated regularly in practice sessions to facilitate correct technique and progression. ${ }^{39}$ All participating coaches were asked to perform the FIFA $11+$ programme with their team as a warm-up at the beginning of all practice and match sessions, at a suggested minimum of two to three times per week.

\section{Daily exposure sheet}

During the season, exposure and adherence data were collected prospectively using a modified version of a previously validated exposure registration form for injury surveillance in youth soccer. ${ }^{41}$ All teams appointed a team designate who was responsible for recording individual exposure at each practice and match session, as well as team-level adherence to the FIFA $11+$, using the daily exposure sheet. ${ }^{39}$ Coach adherence was operationalised as the proportion of team training sessions and games at which the FIFA $11+$ exercises were performed. Player adherence was based on the proportion of sessions at which the team performed the FIFA $11+$, adjusted for individual attendance at those sessions. Coaches and players were divided into 'low' ( $<72 \%$ of sessions), 'medium' (72-91\% of sessions) and 'high' ( $\geq 91 \%$ of sessions) adherence tertile groups.

\section{Analysis}

All analyses were performed using STATA V.12.0 (StataCorp; College Station, Texas, USA). Baseline questionnaire responses were descriptively analysed including all respondents, regardless of whether they completed a postseason questionnaire. Descriptive analyses are reported as proportions with 95\% CIs or medians with ranges and IQRs. Lower limits of the $95 \%$ CIs were truncated at zero, when necessary.

Analysis of changes between baseline and postseason were restricted to respondents who completed questionnaires at both time points. Knowledge, attitudes and belief changes from baseline to postseason were estimated using McNemar's $\chi^{2}$ tests. Logistic regression (yielding OR with 95\% CIs), adjusting for cluster by team, was used to examine the effect of intrinsic factors (age group, competitive level, years of soccer coaching/ playing experience, 1-year injury history), FIFA 11+ delivery method and adherence on postseason injury attitudes and beliefs. Logistic regression, adjusting for cluster by team, was also used to examine the effect of intrinsic factors and delivery method on adherence to the FIFA $11+$ programme.

\section{RESULTS}

\section{Participant characteristics}

Participant flow through the study is presented in figure 1 . Forty-three $(91.5 \%)$ coaches and 385 players (100\%) provided questionnaire responses in the preseason period. Twenty-nine coaches (61.7\%) and $258(67 \%)$ players completed questionnaires at both time points.

Baseline coach and player characteristics are presented in table 1 . The coach sample consisted of 24 head coaches, 21 assistant coaches and 2 team managers (47 'coaches'), but only 43 of these individuals provided baseline characteristic information. 
Figure 1 Proportion of coaches and players responding to the baseline and postseason questionnaires, by randomised group.

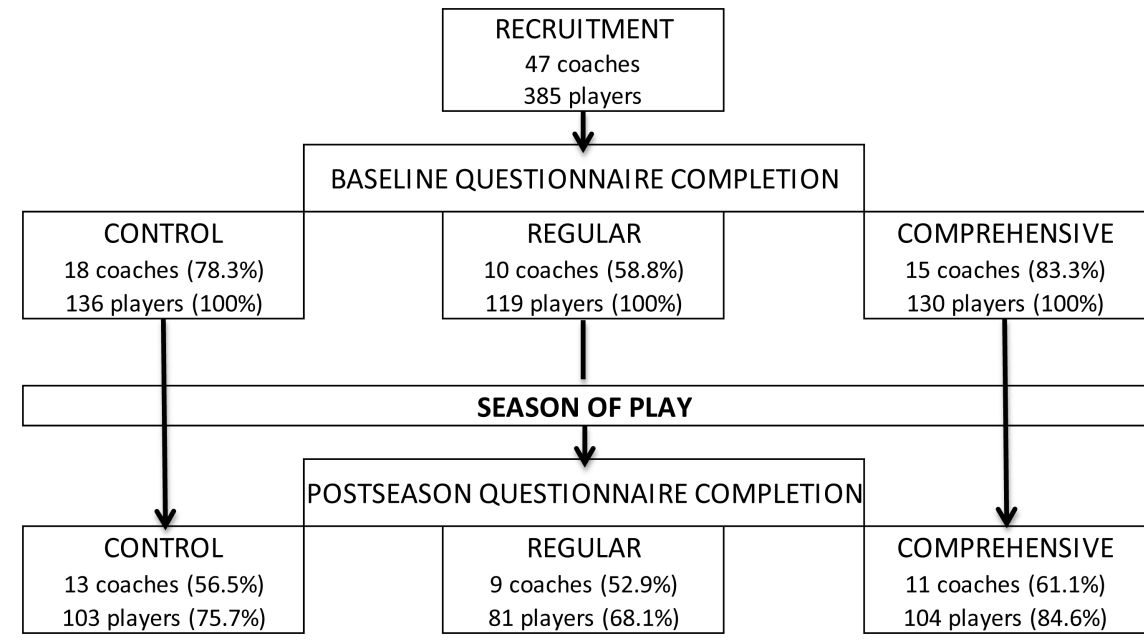

\section{Baseline injury beliefs}

Injury risk beliefs

At baseline, $30.2 \%$ (95\% CI $16.5 \%$ to $44.0 \%$ ) of coaches and $27.8 \%$ (95\% CI $23.3 \%$ to $32.3 \%$ ) of players believed that male and female soccer players had the same overall risk of injury. Beliefs about specific injury risk are presented in table 2 . Coaches and players selected the category 'knees and ankles' as the most commonly injured body parts.

\section{Injury prevention beliefs}

The three injury types (as identified by participants) that were most commonly believed to be preventable were 'muscle injuries, 'knee injuries' and 'ankle injuries'. The most frequently indicated strategies to prevent these injuries are presented in table 3. When asked directly whether they believed that injuries were preventable, coaches were more likely than players to answer 'yes' $(z=-3.90, p=0.0001)$. Attitudes towards who should take responsibility for injury prevention are presented in table 4 .

Table 1 Baseline characteristics of $n=43$ coaches and $n=385$ players from youth soccer in Canada

\begin{tabular}{|c|c|c|}
\hline Characteristic & $\begin{array}{l}\text { Coaches }(n=43) \\
\text { Median (range//QR) } \\
\text { or frequency }(\%)\end{array}$ & $\begin{array}{l}\text { Players ( } n=385) \\
\text { Median (range/lQR) } \\
\text { or frequency (\%) }\end{array}$ \\
\hline \multicolumn{3}{|l|}{ Age group } \\
\hline U16 & $25(58.1)$ & 214 (55.6) \\
\hline U18 & $19 *(44.1)$ & $171(44.4)$ \\
\hline Years coaching experience & $10(0-45 / 5-15)$ & - \\
\hline $\begin{array}{l}\text { Have previous soccer playing } \\
\text { experience }\end{array}$ & $30(69.8)$ & $385(100.0)$ \\
\hline Years of playing experience & $8(0-54 / 5-25)$ & $10(1-15 / 7-11)$ \\
\hline $\begin{array}{l}\text { Experienced a personal time } \\
\text { loss injury playing soccer in } \\
\text { past } 12 \text { months }\end{array}$ & $14(32.6)$ & $194(50.4)$ \\
\hline \multicolumn{3}{|l|}{ Time loss duration } \\
\hline Slight (0-7 days) & $3(21.4)$ & 38 (19.6) \\
\hline Moderate (8-28 days) & $4(28.6)$ & $73(37.6)$ \\
\hline Severe (>28 days) & $5(35.7)$ & $59(30.4)$ \\
\hline Missing & $2(14.3)$ & $24(12.4)$ \\
\hline
\end{tabular}

*One coach was the head coach of a U-14 and a U-16 team (responses are only counted once in the remainder of the table).

\section{Effect of personal characteristics and $11+$ exposure on beliefs \\ Adherence}

Mean team-level adherence to the FIFA $11+$ was $73.5 \%(95 \%$ CI $67.4 \%$ to $79.6 \%$ ) for teams in the 'control' group, $81.3 \%$ (95\% CI $75.7 \%$ to $86.9 \%$ ) for teams in the 'standard' group and $85.6 \%$ (95\% CI $81.8 \%$ to $89.4 \%)$ for teams in the 'comprehensive' group.

\section{Injury risk beliefs}

More players than coaches considered 'inadequate warm-up' as a risk factor for injury at postseason (table 2). Adjusting for team role (coach or player), there was no effect of randomisation group $(\mathrm{OR}=1.1,95 \% \mathrm{CI} 0.8 \%$ to $1.5 \%)$ or adherence $(\mathrm{OR}=1.0 ; 95 \% \mathrm{CI} 0.9 \%$ to $1.1 \%)$ on the belief that inadequate warm-up was a risk factor.

\section{Injury prevention attitudes and beliefs}

At postseason, coaches and players held similar beliefs that injuries were preventable $(\mathrm{z}=-1.76, \mathrm{p}=0.08)$. Coaches and players continued to believe that muscle, knee and ankle injuries were most likely preventable. Overall, there were no significant changes in the strategies believed to prevent these injuries from baseline to postseason (table 3), although significantly more players than coaches thought that warming up could prevent ankle injuries at postseason. There was no effect of randomisation group or adherence tertile on the postseason belief that a warm-up could prevent an injury, for coaches or players.

After adjusting for cluster by team, age group $(\mathrm{OR}=0.1 ; 95 \%$ CI 0.003 to 1.2$)$, competitive level $(\mathrm{OR}=0.6 ; 0.2$ to 2.3$)$, years coaching $(\mathrm{OR}=1.0 ; 0.9$ to 1.1$)$, years playing $(\mathrm{OR}=1.1 ; 0.9$ to 1.2$)$ and 12 -month personal injury history $(\mathrm{OR}=2.5,0.5$ to 12.2) were not associated with baseline coach beliefs that injuries are preventable. At postseason, these factors again had no effect on the belief that injuries are preventable, nor did randomisation group $(\mathrm{OR}=0.6 ; 0.2$ to 1.6$)$ or adherence $(\mathrm{OR}=1.0 ; 0.9$ to 1.1$)$.

Age group $(\mathrm{OR}=0.9 ; 0.3$ to 2.3$)$, competitive level $(\mathrm{OR}=0.6$; 0.3 to 1.1$)$, years playing ( $\mathrm{OR}=1.0 ; 0.9$ to 1.2$)$ and 12 -month personal injury history $(\mathrm{OR}=1.6 ; 0.6$ to 4.1$)$ were not associated with player beliefs that injuries are preventable at baseline. These factors had no effect on postseason beliefs that injuries are preventable. Eighty-two injuries were recorded during the study (details published elsewhere ${ }^{39}$ ); reporting that an injury during the study period had no effect 
Table 2 Coach and player injury risk beliefs (significant baseline differences between coaches and players indicated by $\wedge$ based on $95 \% \mathrm{Cl}$; significant postseason differences between coaches and players indicated by ${ }^{\S}$ based on $95 \% \mathrm{Cl}$; significant within-group differences between baseline and postseason at $p<0.01$ level indicated by *)

\begin{tabular}{|c|c|c|c|c|c|c|}
\hline & \multicolumn{3}{|l|}{$\begin{array}{l}\text { Coach } \\
\%(95 \% \mathrm{Cl})\end{array}$} & \multicolumn{3}{|l|}{$\begin{array}{l}\text { Player } \\
\%(95 \% \mathrm{Cl})\end{array}$} \\
\hline & \multirow{2}{*}{$\begin{array}{l}\text { Whole sample }(n=43) \\
\text { Baseline }\end{array}$} & \multicolumn{2}{|c|}{ Precomparison-postcomparison $(n=29)$} & \multirow{2}{*}{$\begin{array}{l}\text { Whole sample }(n=385) \\
\text { Baseline }\end{array}$} & \multicolumn{2}{|c|}{$\begin{array}{l}\text { Precomparison-postcomparison } \\
(\mathrm{n}=258)\end{array}$} \\
\hline & & Baseline & Postseason & & Baseline & Postseason \\
\hline \multicolumn{7}{|l|}{ Most commonly injured area } \\
\hline Knees and ankles & 88.4 (78.8 to 98.0$)$ & 89.7 (78.6 to 100$)$ & 93.1 (83.9 to 100$)$ & 86.2 (82.8 to 89.7$)$ & $88.0(84.0$ to 92.0$)$ & 89.5 (85.8 to 93.2$)$ \\
\hline Hamstrings and thighs & $4.7(0$ to 11.0$)$ & $4.7(0$ to 12.4$)$ & $0^{\S}$ & 7.5 (4.9 to 10.1$)$ & 5.4 (2.6 to 8.2$)$ & $5.0(2.3$ to 7.7$)$ \\
\hline Other & $7.0(0$ to 14.6$)$ & $6.9(0$ to 16.1$)$ & $6.9(0$ to 16.1$)$ & 3.1 (1.4 to 4.8$)$ & 2.7 (0.7 to 4.7$)$ & 3.1 (1.0 to 5.2$)$ \\
\hline \multicolumn{7}{|l|}{ Injury risk factors } \\
\hline Inadequate warm-up & 62.8 (48.4 to 77.3$)$ & 69.0 (52.2 to 85.8$)$ & $51.7(33.5 \text { to } 69.9)^{\S}$ & 75.8 (71.5 to 80.1$)$ & $77.9(72.8$ to 83.0$)$ & 78.7 (73.7 to 83.7$)$ \\
\hline Lack of stretching/flexibility & $0^{\wedge}$ & 0 & $0^{\S}$ & $57.9(53.0$ to 62.8$)$ & $57.4(51.4$ to 63.4$)$ & $55.8(49.7$ to 61.9$)$ \\
\hline Aggression/risk taking & $16.3(5.3 \text { to } 27.3)^{\wedge}$ & 17.2 (3.5 to 30.9$)$ & 20.7 (6.0 to 35.5$)$ & 43.4 (38.5 to 48.4$)$ & 43.8 (37.8 to 49.9$)$ & 37.6 (31.7 to 43.5$)$ \\
\hline Lack of fitness & $81.4(69.8 \text { to } 93.0)^{\wedge}$ & $96.6(90.0 \text { to } 100)^{*}$ & 65.5 (48.2 to 82.8$)$ & 43.6 (38.7 to 48.6$)$ & 45.0 (38.9 to 51.1$)$ & 43.8 (37.8 to 49.9$)$ \\
\hline Body contact & $0^{\wedge}$ & 0 & $0^{\S}$ & 29.4 (24.9 to 34.0$)$ & 31.4 (25.7 to 37.1$)$ & 32.9 (27.2 to 38.6$)$ \\
\hline Poor muscle strength & $0^{\wedge}$ & 0 & $0^{\S}$ & 23.1 (18.9 to 27.3$)$ & 23.6 (18.4 to 28.8$)$ & 26.4 (21.0 to 31.8$)$ \\
\hline Poor technique & $30.2(16.5 \text { to } 43.9)^{\wedge}$ & 24.1 (8.5 to 39.7 ) & $31.0(14.2$ to 47.8$)$ & $10.1(7.1$ to 13.1$)$ & $10.1(6.4$ to 13.8$)$ & $13.2(9.1$ to 17.3$)$ \\
\hline Player's genetics & $9.3(0.6$ to 18.0$)$ & $6.9(0$ to 16.1$)$ & $3.4(0$ to 10.0$)$ & 3.1 (1.4 to 4.8$)$ & $2.7(0.7$ to 4.7$)$ & $5.0(2.3$ to 7.7$)$ \\
\hline
\end{tabular}

on prevention beliefs $(\mathrm{OR}=1.1 ; 0.3$ to 4.3$)$, nor did randomisation group $(\mathrm{OR}=0.6 ; 0.3$ to 1.3$)$ or adherence $(\mathrm{OR}=1.0$; 0.9 to 1.1$)$.

At postseason, there was no difference in coach or player attitudes towards prevention responsibility. Both groups held the coach equally responsible $(\mathrm{OR}=0.5 ; 0.2$ to 1.4$)$, but players were more likely than coaches to think prevention was the player's responsibility at postseason $(\mathrm{OR}=7.4 ; 3.0$ to 18.2$)$. Randomisation group and adherence to the $11+$ did not affect these relationships.

Table 3 The three injuries most commonly believed to be preventable, and prevention strategies suggested by participants (significant baseline differences between coaches and players indicated by $\wedge$ based on $95 \% \mathrm{Cl}$; significant postseason differences between coaches and players indicated by ${ }^{\S}$ based on $95 \% \mathrm{Cl}$. No significant within-group differences were found)

\begin{tabular}{|c|c|c|c|c|c|c|}
\hline & \multicolumn{3}{|l|}{$\begin{array}{l}\text { Coach } \\
\%(95 \% \text { Cl) }\end{array}$} & \multicolumn{3}{|l|}{$\begin{array}{l}\text { Player } \\
\%(95 \% \mathrm{Cl})\end{array}$} \\
\hline & \multirow{2}{*}{$\begin{array}{l}\text { Whole sample }(n=43) \\
\text { Baseline }\end{array}$} & \multicolumn{2}{|c|}{ Precomparison-postcomparison $(n=29)$} & \multirow{2}{*}{$\begin{array}{l}\text { Whole sample }(n=385) \\
\text { Baseline }\end{array}$} & \multicolumn{2}{|c|}{ Precomparison-postcomparison $(n=258)$} \\
\hline & & Baseline & Postseason & & Baseline & Postseason \\
\hline Muscle injury & 46.5 (31.6 to 61.4$)$ & 41.4 (23.5 to 59.3$)$ & 51.7 (33.5 to 69.9$)$ & 55.1 (50.1 to 60.1$)$ & $55.4(49.3$ to 61.5$)$ & 48.8 (42.7 to 54.9 ) \\
\hline Stretch & $23.3(10.7$ to 35.9$)$ & 24.1 (8.5 to 39.7$)$ & $27.6(11.3$ to 43.9$)$ & 40.5 (35.6 to 45.4$)$ & 38.8 (32.9 to 44.8$)$ & 36.0 (30.1 to 41.9$)$ \\
\hline Strengthen & $2.3(0$ to 6.8$)$ & $3.4(0$ to 10.0$)$ & $3.4(0$ to 10.0$)$ & 8.1 (5.4 to 10.8$)$ & 7.4 (4.2 to 10.6$)$ & 9.7 (6.1 to 13.3$)$ \\
\hline Warm-up & $18.6(7.0$ to 30.2$)$ & $13.8(1.3$ to 26.4$)$ & $10.3(0$ to 21.4$)$ & $9.4(6.5$ to 12.3$)$ & 9.7 (6.1 to 13.3$)$ & $9.3(5.8$ to 12.8$)$ \\
\hline Equipment & $0^{\wedge}$ & 0 & 0 & $4.4(2.4$ to 6.5$)$ & 5.8 (3.0 to 8.7$)$ & $2.7(0.7$ to 4.7$)$ \\
\hline Technique & $0^{\wedge}$ & 0 & $0^{\S}$ & $2.9(1.2$ to 4.6$)$ & $3.1(1.0$ to 5.2$)$ & $5.4(2.6$ to 8.2$)$ \\
\hline Other & 2.3 (0 to 6.8$)$ & 0 & $10.3(0$ to 21.4$)$ & $9.6(6.7$ to 12.5$)$ & $11.2(7.4$ to 15.1$)$ & 8.5 (5.1 to 11.9$)$ \\
\hline Knee injury & $44.2(29.4 \text { to } 59.0)^{\wedge}$ & 41.4 (23.5 to 59.3$)$ & $51.7(33.5 \text { to } 69.9)^{\S}$ & 18.7 (14.8 to 22.6 ) & 19.0 (14.2 to 23.8$)$ & $12.0(8.0$ to 16.0$)$ \\
\hline Stretch & $0^{\wedge}$ & 0 & $0^{\S}$ & 11.7 (8.5 to 14.9 ) & $11.6(7.7$ to 15.5$)$ & 9.3 (5.8 to 12.8$)$ \\
\hline Strengthen & $27.9(14.5$ to 41.3$)$ & 13.8 (1.3 to 26.4$)$ & 27.6 (11.3 to 43.9$)$ & $15.3(11.7$ to 18.9$)$ & $14.3(10.0$ to 18.6$)$ & 9.7 (6.1 to 13.3$)$ \\
\hline Warm-up & $0^{\wedge}$ & 0 & 0 & 4.2 (2.2 to 6.2$)$ & 4.7 (2.1 to 7.3 ) & $1.2(0$ to 2.5$)$ \\
\hline Equipment & 0 & 13.8 (1.3 to 26.4$)$ & $3.4(0$ to 10.0$)$ & $1.3(0.2$ to 2.4$)$ & $1.6(0.1$ to 3.1$)$ & 0.4 (0 to 1.2$)$ \\
\hline Technique & $9.3(0.6$ to 18.0$)$ & 10.3 (0 to 21.4 ) & $6.9(0$ to 16.1$)$ & $2.9(1.2$ to 4.6$)$ & 3.1 (1.0 to 5.2$)$ & $1.2(0$ to 2.5$)$ \\
\hline Other & 7.0 (0 to 14.6$)$ & $3.4(0$ to 10.0$)$ & 13.8 (1.3 to 26.4$)$ & $5.2(0.2$ to 7.4$)$ & 4.3 (1.8 to 6.8 ) & 3.1 (1.0 to 5.2 ) \\
\hline Ankle injury & 25.6 (12.6 to 38.6$)$ & 20.7 (6.0 to 35.5$)$ & 27.6 (11.3 to 43.9$)$ & 28.8 (24.3 to 33.3$)$ & 31.4 (25.7 to 37.1$)$ & 29.1 (23.6 to 34.6 ) \\
\hline Stretch & $2.3(0 \text { to } 6.8)^{\wedge}$ & $3.4(0$ to 10.0$)$ & $6.9(0$ to 16.1$)$ & $16.4(12.7$ to 20.1$)$ & $18.2(13.5$ to 22.9$)$ & $18.2(13.5$ to 22.9$)$ \\
\hline Strengthen & 11.6 (2.0 to 21.2 ) & $13.8(1.3$ to 26.4$)$ & $10.3(0$ to 21.4$)$ & 7.8 (5.1 to 10.5$)$ & 9.7 (6.1 to 13.3$)$ & 10.9 (7.1 to 14.7$)$ \\
\hline Warm-up & $0^{\wedge}$ & 0 & $0^{\S}$ & 4.2 (2.2 to 6.2 ) & 4.7 (2.1 to 7.3$)$ & 4.3 (1.8 to 6.8 ) \\
\hline Equipment & $0^{\wedge}$ & 0 & $0^{\S}$ & 7.0 (4.5 to 9.6 ) & 6.6 (3.6 to 9.6$)$ & 7.8 (4.5 to 11.1$)$ \\
\hline Technique & 2.3 (0 to 6.8 ) & 0 & $6.9(0$ to 16.1$)$ & 3.6 (1.7 to 5.5$)$ & 3.5 (1.3 to 5.7$)$ & $1.9(0.2$ to 3.6$)$ \\
\hline Other & $9.3(0.6$ to 18.0$)$ & $3.4(0$ to 10.0$)$ & 3.4 (0 to 10.0$)$ & 7.0 (4.5 to 9.6 ) & 6.6 (3.6 to 9.6 ) & 6.2 (3.3 to 9.1$)$ \\
\hline
\end{tabular}

Bold typeface values highlight the proportion believing that these types of injuries are preventable, whereas the non-bold text gives proportions endorsing various prevention strategies for those types of injuries.

Category 'other' includes rest, less aggressive behaviour, fitness. 
Table 4 Beliefs about who is responsible for injury prevention (significant baseline differences between coaches and players indicated by $\wedge$ based on $95 \% \mathrm{Cl}$; significant postseason differences between coaches and players indicated by ${ }^{\S}$ based on $95 \%$ Cl. No significant within-group differences were found)

\begin{tabular}{|c|c|c|c|c|c|c|}
\hline & \multicolumn{3}{|l|}{$\begin{array}{l}\text { Coach } \\
\%(95 \% \mathrm{Cl})\end{array}$} & \multicolumn{3}{|l|}{$\begin{array}{l}\text { Player } \\
\%(95 \% \mathrm{Cl})\end{array}$} \\
\hline & \multirow{2}{*}{$\begin{array}{l}\text { Whole sample }(n=43) \\
\text { Baseline }\end{array}$} & \multicolumn{2}{|c|}{$\begin{array}{l}\text { Precomparison-postcomparison } \\
(\mathrm{n}=29)\end{array}$} & \multirow{2}{*}{$\begin{array}{l}\text { Whole sample }(n=385) \\
\text { Baseline }\end{array}$} & \multicolumn{2}{|c|}{$\begin{array}{l}\text { Precomparison-postcomparison } \\
(\mathrm{n}=258)\end{array}$} \\
\hline & & Baseline & Postseason & & Baseline & Postseason \\
\hline \multicolumn{7}{|c|}{ Who is responsible for injury prevention? } \\
\hline Coach & $93.0(85.4 \text { to } 100)^{\wedge}$ & 93.1 (83.9 to 100$)$ & 86.2 (73.7 to 98.8$)$ & 74.5 (70.2 to 78.9$)$ & 73.3 (67.9 to 78.7$)$ & 77.1 (72.0 to 82.2 ) \\
\hline Players & 90.7 (82.0 to 99.4$)$ & 89.7 (78.6 to 100$)$ & $69.0(52.2 \text { to } 85.8)^{\S}$ & 95.3 (93.2 to 97.4$)$ & 96.1 (93.7 to 98.5$)$ & 95.3 (92.7 to 97.9$)$ \\
\hline Parents & $65.1(50.9 \text { to } 79.4)^{\wedge}$ & $62.1(44.4$ to 79.8$)$ & $55.2(37.1 \text { to } 73.3)^{\S}$ & $13.0(9.6$ to 16.4$)$ & $12.4(8.4$ to 16.4$)$ & $13.6(9.4$ to 17.8$)$ \\
\hline League or club administration & $18.6(7.0 \text { to } 30.2)^{\wedge}$ & 17.2 (3.5 to 30.9 ) & 20.7 (6.0 to 35.5$)$ & 4.7 (2.6 to 6.8$)$ & 3.9 (1.5 to 6.3$)$ & 5.4 (2.6 to 8.2$)$ \\
\hline Referee & $16.3(5.3$ to 27.3$)$ & 13.8 (1.3 to 26.4$)$ & $17.2(3.5 \text { to } 30.9)^{\S}$ & 30.6 (26.0 to 35.2 ) & 29.1 (23.6 to 34.6) & 39.1 (33.2 to 45.1$)$ \\
\hline Medical personnel & $7.0(0 \text { to } 14.6)^{\wedge}$ & $10.3(0$ to 21.4$)$ & $0^{\S}$ & 36.6 (31.8 to 41.4$)$ & $38.0(32.1$ to 43.9$)$ & 28.3 (22.8 to 33.8$)$ \\
\hline
\end{tabular}

\section{Effect of intrinsic factors on adherence}

For coaches, there was no significant effect of age group $(\mathrm{OR}=2.8 ; 0.4$ to 18.5$)$, tier $(\mathrm{OR}=1.1 ; 0.2$ to 5.3$)$, years of coaching $(\mathrm{OR}=1.0 ; 95 \% \mathrm{CI} 0.9$ to 1.1$)$, 12-month personal injury history $(\mathrm{OR}=0.7 ; 0.3$ to 1.6$)$ or belief that injuries are preventable $(\mathrm{OR}=0.4 ; 0.1$ to 3.7$)$ on being in the upper tertile of adherence, after adjusting for cluster by team. For players, no effect of age group $(\mathrm{OR}=0.9 ; 0.6$ to 1.4$)$, tier $(\mathrm{OR}=1.7 ; 0.9$ to $3.2), 12$-month personal injury history $(\mathrm{OR}=0.9 ; 0.6$ to 1.4$)$ or belief that injuries are preventable $(\mathrm{OR}=0.7 ; 0.3$ to 1.9$)$ on high adherence was found.

Years of playing experience were negatively associated with high adherence for coaches $(\mathrm{OR}=0.93 ; 0.88$ to 0.99$)$ and players $(\mathrm{OR}=0.92 ; 0.85$ to 0.98$)$.

\section{DISCUSSION}

Coaches and players were accurate in their beliefs that knees and ankles are the most commonly injured body parts in soccer but, contrary to previous studies, there was no effect of personal factors (eg, age group, playing tier, injury history) on their overall injury prevention beliefs. ${ }^{30}{ }^{42}$ Short et al ${ }^{42}$ examined the relationship between personal injury history and prevention beliefs in college soccer, and found that female players who had a history of injury reported greater risk perceptions than their uninjured peers. Conversely, those without a previous injury exhibited high confidence in their ability to avoid being injured. ${ }^{42}$ Our finding that injury history and reporting an injury during the study were unrelated to risk beliefs could reflect age-related differences in prevention self-efficacy or risk perceptions. It could also be the result of social norming within the team, whereby the influence of peer or coach beliefs affects risk perceptions more than one's own experiences. Both of these possibilities bear further investigation in order to identify potentially modifiable factors to target with specific intervention delivery strategies.

Approximately 40-50\% of coaches believed that knee injuries could be prevented at baseline and postseason, which is slightly lower than the $62 \%$ reported by Orr et $a l^{17}$ in a sample of youth coaches from the same geographical area. However, fewer than $20 \%$ of players believed that knee injuries were preventable at baseline and postseason, which is considerably lower than the $46 \%$ reported in the Orr et $a l^{17}$ study. Neither coaches nor players demonstrated a significant improvement in knee injury prevention beliefs after exposure to the FIFA $11+$ programme. This suggests that the participants in our study were less aware of injury risk than their peers at baseline, and that the delivery strategies for the $11+$ were insufficient for translating new injury risk information. ${ }^{18} 27$

Players most commonly endorsed stretching as a prevention strategy. In 1998, a study conducted in English professional soccer found that players believed poor flexibility or lack of stretching to be a risk factor for injury. ${ }^{23}$ Despite evidence to the contrary, ${ }^{43-45}$ our results suggest that this belief is still prevalent in the sport community, but not for coaches. Only a small proportion of coaches believed stretching would prevent injuries at baseline or postseason, indicating that coaches may have accurate beliefs about the value of stretching, but do not effectively transmit this knowledge to players. This indicates that current delivery strategies for the FIFA $11+$ programme do not ensure that accurate evidence is mobilised to the target audience, nor do they effectively address incorrect or outdated prevention beliefs. This is one potential reason that uptake of the programme is low in community sport, and highlights the fact that basic knowledge dissemination is insufficient for changing established thought or action patterns.

Although 'inadequate warm-up' was identified as a risk factor by coaches and players, very few endorsed warming up as a strategy for reducing injuries. Postseason, significantly more players than coaches thought a poor warm-up was a risk factor, but there was no change in the proportions of coaches or players who identified warming up as a prevention technique, regardless of adherence to the FIFA $11+$. The reason for this discrepancy is unclear, but it highlights the need for improved understanding of the rationale behind the $11+$ in the soccer community. It also indicates that, although delivering prevention programmes through coaches may be the most feasible method of reaching a large group of community-based athletes, additional effort must be made to ensure that coaches are able to accurately translate information, beyond just the content of the intervention, to their teams.

The only personal factor associated with adherence to the $11+$ programme was years of playing experience. It appears that the longer coaches and players have been active in soccer, the less likely they are to perform the $11+$ at every training and match session. This could suggest either that more experienced individuals think the programme is only suited to novice teams, or that they feel more confident in making their own decisions about the best warm-up to do. FIFA $11+$ delivery may therefore need to be tailored to the audience, and focusing on the potential performance benefits associated with the programme may 
better appeal to more experienced players and coaches than an injury prevention message alone. ${ }^{27} 46$

\section{Limitations}

Participants were not asked directly about previous exposure to the FIFA $11+$. It is unclear whether experience with the programme would have increased or decreased risk perceptions, but it is likely that risk awareness would be higher for these individuals, leading to an overestimation of baseline knowledge in our sample. Furthermore, it is possible that self-report beliefs were subject to social desirability bias, considering that the questionnaires were completed in a team setting. ${ }^{47}$ All efforts were made to ensure that respondents had adequate privacy in which to complete the questionnaires, but we cannot account for potential under-reporting of risk perception or over-reporting of intention by athletes wishing to conform to social norms within the team. As data were collected as part of a larger injury prevention study, there was also a risk of selection bias. Teams may have chosen to participate in the larger study because of greater baseline injury risk perceptions, which might have inflated our baseline injury risk and prevention belief estimates and, consequently, limited changes between baseline and postseason. As adherence was collected at the team level, we were also unable to relate personal characteristics to individual adherence. Although it is reasonable to assume that all players in attendance at a team session participated in the team warm-up when it was performed, future studies should account for this objectively.

This study is also limited to adolescent female players in a competitive Canadian league, and therefore may not be generalisable to boys, younger or older athletes, different levels of play, different sports or those in other geographical areas.

\section{Future directions}

As adherence to the $11+$ does not appear to depend on injury knowledge or beliefs on the part of either coaches or players, it is recommended that studies further examine coach and player motivations for engaging in injury prevention programmes. ${ }^{28}$ Future studies should also correlate player views to those of their coaches, to account for the influence of coach beliefs on player beliefs, and subsequent team behaviour. It will also be important to understand the apparent discrepancy between believing that an inadequate warm-up is a risk factor for injury, but not believing that a warm-up can prevent injury. Moreover, direct exposure to the $11+$ as it was delivered in this study appears to be insufficient for changing beliefs or behaviour over the course of one playing season. Different delivery strategies and longer follow-up periods may yield important information for improving FIFA $11+$ uptake in community soccer.

\section{CONCLUSIONS}

This study has demonstrated substantial gaps in knowledge and beliefs in the female youth soccer community, particularly related to injury risk factors and effective prevention strategies, and these differ for coaches and players. Yet, these beliefs did not have significant effects on adherence to the FIFA $11+$, suggesting that additional motivational factors should be considered. Moreover, personal characteristics such as injury history and exposure to an injury prevention intervention did not influence adherence, although it appears that greater playing experience leads to poorer programme uptake. This has important implications for the implementation of prevention programmes, and suggests a need for population-targeted strategies.

\section{What are the new findings?}

- There were different gaps in injury knowledge for coaches and female youth soccer players.

- Injury risk and prevention beliefs did not significantly influence adherence to the FIFA 11+ warm-up programme.

- Coaches and players with more years of experience were less likely to adhere to the FIFA $11+$ programme.

\section{How might it impact on clinical practice in the near future?}

Delivery strategies for injury prevention programmes must be tailored to coach and player audiences to account for different baseline injury risk knowledge and prevention beliefs, as well as sport-playing experience.

Acknowledgements The authors would like to thank all the research assistants, study therapists and physicians, coaches and players who participated in this project.

Contributors KS, MR, CFF and CAE were responsible for the conception and design of the study. KS, MR and CAE coordinated the study and managed all aspects, including data collection. CDM conducted all analyses and wrote the first draft of the manuscript. All authors had full access to the data and contributed to the interpretation of the findings and critical revision of the manuscript.

Funding This study was funded by the FIFA Medical Assessment and Research Centre (F-MARC), the Alberta Children's Hospital Research Institute for Child and Maternal Health Professorship in Pediatric Rehabilitation, supported by the Alberta Children's Hospital Foundation and Alberta Team Osteoarthritis, supported by Alberta Innovates Health Solutions. CFF was funded from a National Health and Medical Research Council (of Australia) (NHMRC) Principal Research Fellowship (ID:565900). The Sport Injury Prevention Research Centre, the Oslo Sports Trauma Research Centre, and the Australian Centre for Research into Injury in Sport and its Prevention (ACRSIP) are three of the four International Research Centres for Prevention of Injury and Protection of Athlete Health supported by the IOC. The Oslo Sports Trauma Research Center has been established at the Norwegian School of Sport Sciences through generous grants from the Royal Norwegian Ministry of Culture, the South-Eastern Norway Regional Health Authority, the Norwegian Olympic Committee \& Confederation of Sport and Norsk Tipping AS.

Competing interests None.

Ethics approval Conjoint Health Research Ethics Board, University of Calgary.

Provenance and peer review Not commissioned; externally peer reviewed.

\section{REFERENCES}

1 Emery CA, Meeuwisse WH, McAllister JR. A survey of sport participation, sport injury and sport safety practices in adolescents. Clin J Sport Med 2006;16:20-6.

2 Emery CA, Meeuwisse WH. The effectiveness of a neuromuscular prevention strategy to reduce injuries in youth soccer: a cluster-randomised controlled trial. $\mathrm{Br} J$ Sports Med 2010;44:555-62.

3 Soligard T, Myklebust G, Steffen K, et al. Comprehensive warm-up programme to prevent injuries in young female footballers: cluster randomised controlled trial. BMJ 2008;337:a2469.

4 Junge $A$, Rosch $D$, Peterson $L$, et al. Prevention of soccer injuries: a prospective intervention study in youth amateur players. Am J Sports Med 2002;30:652-9.

5 Heidt RS Jr, Sweeterman LM, Carlonas RL, et al. Avoidance of soccer injuries with preseason conditioning. Am J Sports Med 2000;28:659-62.

6 Mandelbaum BR, Silvers HJ, Watanabe DS, et al. Effectiveness of a neuromuscular and proprioceptive training program in preventing anterior cruciate ligament injuries in female athletes: 2-year follow-up. Am J Sports Med 2005;33:1003-10.

7 Kiani A, Hellquist $E$, Ahlqvist $K$, et al. Prevention of soccer-related knee injuries in teenaged girls. Arch Intern Med 2010;170:43.

8 Waldén $\mathrm{M}$, Atroshi I, Magnusson $\mathrm{H}$, et al. Prevention of acute knee injuries in adolescent female football players: cluster randomised controlled trial. BMJ 2012;344:e3042

9 Soligard T, Nilstad A, Steffen K, et al. Compliance with a comprehensive warm-up programme to prevent injuries in youth football. Br J Sports Med 2010;44:787-93. 
10 Steffen K, Emery CA, Romiti M, et al. High adherence to a neuromuscular injury prevention programme (FIFA 11+) improves functional balance and reduces injury risk in Canadian youth female football players: a cluster randomized trial. $\mathrm{Br} J$ Sports Med 2013;47:794-802.

11 Hägglund $M$, Atroshi I, Wagner $P$, et al. Superior compliance with a neuromuscular training programme is associated with fewer $A C L$ injuries and fewer acute knee injuries in female adolescent football players: secondary analysis of an RCT. Br J Sports Med 2013;47:974-9.

12 Finch C. A new framework for research leading to sports injury prevention. J Sci Med Sport 2006:9:3-9.

13 Finch $C$, Donaldson $A$. A sports setting matrix for understanding the implementation context for community sport. Br J Sports Med 2010:44:973-8.

14 Finch $C$. No longer lost in translation-the art and science of sports injury prevention implementation research. Br J Sports Med 2011:45:1253-7.

15 Finch C. Implementing and evaluating interventions. In: Baker S, Li G, eds. Injury research: theories, methods, and approaches. New York: Springer, 2012:619-39.

16 Keats $M$, Emery C, Finch C. Are we having fun yet? Fostering adherence to injury preventive exercise recommendations in young athletes. Sports Med 2012;42:175-84.

17 Orr B, Brown C, Hemsing J, et al. Female soccer knee injury: observed knowledge gaps in injury prevention among players/parents/coaches \& current evidence (the KNOW study). Scan J Sport Med 2013;23:271-80.

18 Carter AF, Muller R. A survey of injury knowledge and technical needs of junior rugby union coaches in Townsville (North Queensland). J Sci Med Sport 2008;11:167-73.

19 Twomey $D$, Finch $C F$, Roediger $E$, et al. Preventing lower limb injuries: is the latest evidence being translated into the football field? J Sci Med Sport 2008:12:452-6.

20 Onyeaso CO, Adegbesan OA. Knowledge and attitudes of coaches of secondary school athletes in Ibadan, Nigeria regarding oro-facial injuries and mouthguard use by the athletes. Dent Traumatol 2003:19:204-8.

21 Bell PA. Spondylosis in fast bowlers: principles of prevention and a survey of awareness among cricket coaches. Br J Sports Med 1992:26:273-5.

22 Iversen MD, Friden C. Pilot study of female high school basketball players' anterior cruciate ligament injury knowledge, attitudes, and practices. Scan J Med Sci Sports 2009:19:595-602.

23 Ma W. Basketball players' experience of dental injury awareness about mouthguard in China. Dent Traumatol 2008:24:430-4.

24 Hawkins RD, Fuller CW. A preliminary assessment of footballers' awareness of injury prevention strategies. Br J Sports Med 1998;32:140-3.

25 McGlashan A, Finch CF. The extent to which behavioural and social sciences theories and models are used in sport injury prevention research. Sports Med 2010;40:841-58

26 Arnason A, Engebretsen L, Bahr R. No effect of a video-based awareness program on the rate of soccer injuries. Am J Sports Med 2005;33:77-84.

27 Finch CF, White $\mathrm{P}$, Twomey $\mathrm{D}$, et al. Implementing an exercise-training programme to prevent lower-limb injuries: considerations for the development of a randomised controlled trial intervention delivery plan. Br J Sports Med 2011;45:791-6.

28 White $\mathrm{P}$, Otago L, Saunders L, et al. Ensuring implementation success. How should coach injury prevention education be improved if we want coaches to deliver safety programs during training sessions? Br J Sports Med 2014;48:402-3.
29 Sawyer RJ, Hamdallah M, White D, et al. High school coaches' assessments, intentions to use, and use of a concussion prevention toolkit: Centres for Disease Control and Prevention's heads up: concussion in high school sports. Health Promo Pract 2012;11:34-43.

30 Kroncke E, Niedfeldt MW, Young CC. Use of protective equipment by adolescents in inline skating, skateboarding, and snowboarding. Clin J Sport Med 2008;18:38-43.

31 Miller MG, Berry DC, Gariepy GS, et al. Attitudes of high school ice hockey players toward mouthguard usage. Internet J Allied Health Sci Pract 2006;4:1-6.

32 De Nooijer J, De Wit M, Steenhuis I. Why young Dutch in-line skaters do (not) use protective equipment. Eur J Pub Health 2004;14:178-81.

33 Finch CF, McIntosh AS, McCrory P, et al. A pilot study of the attitudes of Australian Rules footballers towards protective headgear. J Sci Med Sport 2003;6:505-11.

34 Pettersen JA. Does rugby headgear prevent concussion? Attitudes of Canadian players and coaches. Br J Sports Med 2002;36:19-22.

35 Finch C, Donohue S, Garnham A. Safety attitudes and beliefs of junior Australian football players. Inj Prev 2002;8:151-4.

36 Finch CF, Mclntosh AS, McCrory P. What do under 15 year old schoolboy rugby union players think about protective headgear? Br J Sports Med 2001;35:89-94.

37 Kontos AP. Perceived risk. Risk taking, estimation of ability and injury among adolescent sport participants. J Pediatr Psychol 2004:29:447-55.

38 Gilchrist J, Mandelbaum BR, Melancon $\mathrm{H}$, et al. A randomized controlled trial to prevent noncontact anterior cruciate ligament injury in female collegiate soccer players. Am J Sports Med 2008;36:1476-83.

39 Steffen $\mathrm{K}$, Meeuwisse WH, Romiti M, et al. Evaluation of how different implementation strategies of an injury prevention programme (FIFA 11+) impact team adherence and injury risk in Canadian female youth football players: a cluster-randomised trial. Br J Sports Med 2013:47:480-7.

40 Saunders N, Otago L, Romiti M, et al. Coaches' perspectives on implementing an evidence-informed injury prevention programme in junior community netball. $\mathrm{Br} \mathrm{J}$ Sports Med 2010;44:1128-32.

41 Emery CA, Meeuwisse WH, Hartmann SE. Evaluation of risk factors for injury in adolescent soccer: implementation and validation of an injury surveillance system. Am J Sports Med 2005:33:1882-91.

42 Short SE, Reuter J, Brandt J, et al. The relationships among three components of perceived risk of injury, previous injuries and gender in contact sport athletes. Athl Insight 2004;6:38-46.

43 Pope RP, Herbert RD, Kirwan JD, et al. A randomized trial of preexercise stretching for prevention of lower-limb injury. Med Sci Sports Exerc 2000;32:271-7.

44 Parkkari J, Kujala UM, Kannus P. Is it possible to prevent sports injuries? Review of controlled clinical trials and recommendations for future work. Sports Med 2001;31:985-95.

45 Thacker SB, Gilchrist J, Stroup DF, et al. The impact of stretching on sports injury risk: a systematic review of the literature. Med Sci Sports Exerc 2004;36:371-8.

46 Finch CF, Doyle TLA, Dempsey AR, et al. What do community football players think about different exercise-training programmes? Implications for the delivery of lower limb injury prevention programmes. Br J Sports Med 2014:48:702-7.

47 Brener ND, Billy JOG, Grady W. Assessment of factors affecting the validity of self-reported health-risk behavior among adolescents: evidence from the scientific literature. J Adolesc Health 2003:33:436-57. 